\title{
Development of a Method of Internal Reference Price for Redistribution of Energy Imbalances in Balancing Groups
}

Jordanka Angelova*

Gergana Kulina - Radeva**

\section{Abstract}

The market of electrical energy /EE/ in Bulgaria has been liberated completely since 1 July 2007. Consumers who are out on the free market have to negotiate the price of EE and to plan on an hourly basis the quantities to be consumed. Any deviation takes them to the balancing market where the prices for the deficit and surplus of energy are unfavorable when compared with market prices. It is a good solution for those consumers to optimize their expenses for EE by joining a balancing group /BG/. Through their participation in a $B G$ consumers have the best choice and the opportunity to optimize their expenses for imbalances by transferring the responsibility for balancing to the Coordinator of the balancing group /CBG/. CBG is responsible for distributing the total imbalance of the $B G$ among its members, as well as for the prices of the balancing energy within the group. This is what has made the authors of this paper develop and test a method of optimal redistribution of energy imbalances that will lead to the optimization of the financial result of the participants in the balancing group.
Keywords: Electrical energy /EE/; Balancing market; Balancing groups /BG/; Coordinator of balancing groups /CBG/; Imbalances.

JEL: Q41

\section{INTRODUCTION}

$\mathrm{n}$ the liberalized electricity market consumers are able to optimize their costs of imbalances by transferring the responsibility for balancing to the Coordinator of Balancing Group /CBG/. CBG is required to determine the model of distribution of total unbalance among the members and the price of balancing energy in the group. These models are developed and determined by $\mathrm{CBG}$, reflecting management capabilities of the effects of the participation of the members in the balancing group. Each of the models leads to the optimization of the financial result for balancing group members. In order to select the correct model, it is necessary that the different models should be analyzed and their effectiveness for the balancing group evaluated.

The need for developing a method of optimal distribution of imbalances in a BG arises from the fact that not all quantities of imbalances in the group are netted. The $B G$ realizes the imbalances which are traded on the balancing market of ESO (Electricity

* Assoc. Prof. Dr., Technical University - Sofia, 1700 Sofia, IEIM Department

* Dr. Master of Economics, Technical University - Sofia, 1700 Sofia, IEIM Department 


\section{Articles}

System Operator). In this case the CBG has to distribute these imbalances among participants in the group. That redistribution of the Imbalances in the BG should be based on common principles and on a common method. The method the authors will present in this paper is related to the redistribution of imbalances in BG. (Adamov, Holst, Zahariev, 2006; Angelova, J. 2008; Anderson, Settle, 2002; Barz, 2000; Harris, 2006; Weron, 2006).

The development of such a method needs to take into account the following characteristics:

- The method has to be fully effective;

- The method has to guarantee fairness and equality among the participants in the group;

- The method has to be clear and comprehensible enough for the participants in the group;

- The method has to guarantee a distribution of the group effect of balancing among all participants in the group;

- The method has to consider the individual preciseness of energy consumption forecasting of each participant.

It is also necessary to take into account the fact that the calculated sum of the imbalances of each participant of the group for each period of settlement cannot exceed the sum for the imbalances for the same participant for the same period of settlement. All of the above have motivated the authors to come up with a method of optimal distribution of energy imbalances in a BG: the so called Method of Internal Reference Price. The authors have developed a method of optimal distribution of energy imbalances in a balancing group, and in developing it their aim is for its application to lead to a redistribution of the imbalances among the participants in the BG in an optimal way. In developing the method, the authors
Development of a Method of Internal Reference Price for

Redistribution of Energy Imbalances in Balancing Groups

have used Internal Trading Price /ITP/. That is the price at which the netted surplus and deficit quantities are paid for in the BG. It is determined by $C B G$ and can be formed in the following way:

$$
I T P=\left(\frac{\text { PESeso }+ \text { PEDeso }}{2}\right)
$$

where:

PESeso is the price of energy surplus on the balancing market of ESO in leva for $\mathrm{MWh}$;

PEDeso is the price of energy deficit on the balancing market of ESO in leva for MWh.

The prices of the surplus and deficit of EE on the balancing market are determined by ESO according to the adopted by EWRC "Methodology of determining the prices of balancing energy", Annex to RTEE (EWRC, 2014, EA). As the CBG cannot influence the prices of surplus and deficit on the balancing market of ESO directly, they are used in this method of optimal distribution of imbalances in a BG.

The values of the prices of surplus and deficit on the balancing market of ESO for May 2014 have been used because after that month the data about the prices of the surplus and deficit are not public and are individual for each market participant. Then the price of $186.31 \mathrm{IV}$. per MWh was the cost of the deficit, and $28.80 \mathrm{lv}$. per MWh was the cost of the surplus, or:

$$
\begin{aligned}
& \text { PESeso }=28.80 \mathrm{lv} . / \mathrm{MWh} \\
& \text { PEDeso }=186.31 \mathrm{lv} . / \mathrm{MWh}
\end{aligned}
$$

The quantity in the group, which is netted for period $t$, is determined on the basis of the quantity of energy surplus /QES/ produced and the quantity of energy deficit /QED/ in the group i.e. the positive value and negative value are mutually neutralized and depending on the result, if it is a positive value, we get a netted surplus /NS/, respectively if it is a 


\section{Articles}

negative value we get a netted deficit /ND/ as follows:

$$
N S_{t}=N D_{t}=\left|\sum Q E S_{t}-\sum Q E D_{t}\right|
$$

where:

$N S_{t}$ is the quantity of surplus in $\mathrm{MW}$, netted in a group for period $t$;

$N D_{t}$ is the quantity of deficit in MW, netted in a group for period t;

$\sum Q E S_{t}$ is the sum of the quantities of energy surplus of all participants in the group for period t;

$\sum Q E D_{t}$ is the sum of the quantities of energy deficit of all participants in the group.

\section{METHOD OF INTERNAL REFERENCE PRICE}

This is a method which does not involve physical balancing of the participants in the group. Imbalances in the group are traded according to an internal reference price of surplus and deficit, set by CBG. During the period of settlement each participant in the group pays for the surplus and/or deficit they have according to that internal reference price.

In developing the method, the authors have assumed that the internal reference price of surplus and deficit is the same for all participants in the group.

The internal reference price of surplus $\left(\operatorname{IRPS}_{t}\right)$, according to which CBG pays surplus to each participant in the group, is calculated using the following formula:

$$
I R P S_{t}=\frac{N S_{t} \times I T P_{t}+\sum Q E \text { Seso }_{t} \times \text { PESeso }_{t}}{\sum Q E S_{t}}
$$

where:

$I R P S_{t}$ is the internal reference price of surplus for period $t$;

$N S_{t}$ is the quantity of surplus in $\mathrm{MW}$, netted in the group for period $t$ and respectively:

$$
N S_{t}=\left|\sum Q E S_{t}-\sum Q E D_{t}\right|
$$

$\sum Q E S_{t}$ is the sum of the quantities of energy surplus of all participants in the group for period t;

$\sum Q E D_{t}$ is the sum of the quantities of energy deficit of all participants in the group for period $\mathrm{t}$;

$I T P_{t}$ is the internal trade price for period $\mathrm{t}$;

QESeso $_{t}$ is the quantity of energy surplus for the whole BG for period $t$, which goes to the balancing market of ESO;

$\mathrm{PESeso}_{t}$ is the price of surplus on the balancing market of ESO EAD for period $t$.

The internal reference price of deficit $\left(\right.$ IRPD $\left.D_{t}\right)$, according to which CBG pays deficit to each participant in the group, is calculated using the following formula:

$$
I R P D_{t}=\frac{N D_{t} \times I T P_{t}+\sum Q E \text { Deso }_{t} \times \text { PEDeso }_{t}}{\sum Q E D_{t}}
$$

where:

$N D_{t}$ is the quantity deficit in MWs, netted in the group for period $t$ and respectively:

$N D_{t}=N S_{t}=\left|\sum Q E S_{t}-\sum Q E D_{t}\right|$

$I T P_{t}$ is internal trading price for period $t$;

QEDeso $_{t}$ is the quantity of energy deficit for the whole BG for period $t$, which goes to the balancing market of ESO;

$\mathrm{PEDeso}_{t}$ is the price of energy deficit on the balancing market of ESO for period $t$.

In order to demonstrate how the method works, the authors have studied a sample group of 4 participants, shown in Fig. 1, within which:

- participant 1 has planned to consume $5 \mathrm{MWh}$, but has practically consumed 6 MWh i.e. was short of $1 \mathrm{MWh}$ and in this way has produced a deficit;

- participant 2 has consumed 15 MWh but has planned to consume $18 \mathrm{MWh}$, i.e. has a surplus of $3 \mathrm{MWh}$;

- participant 3 has planned to consume $10 \mathrm{MWh}$, but has actually consumed 12 MWh., 2 MWh more i.e. has run a deficit of $2 \mathrm{MWh}$; 


\section{Articles}

- participant 4 has consumed 25 MWh, and has planned to consume $29 \mathrm{MWh}$, i.e. has run a surplus of $4 \mathrm{MWh}$.

Thus, it can be said that the sample BG has run a total surplus of $7 \mathrm{MWh}$. and a deficit of $3 \mathrm{MWh}$. The quantity in the group, which

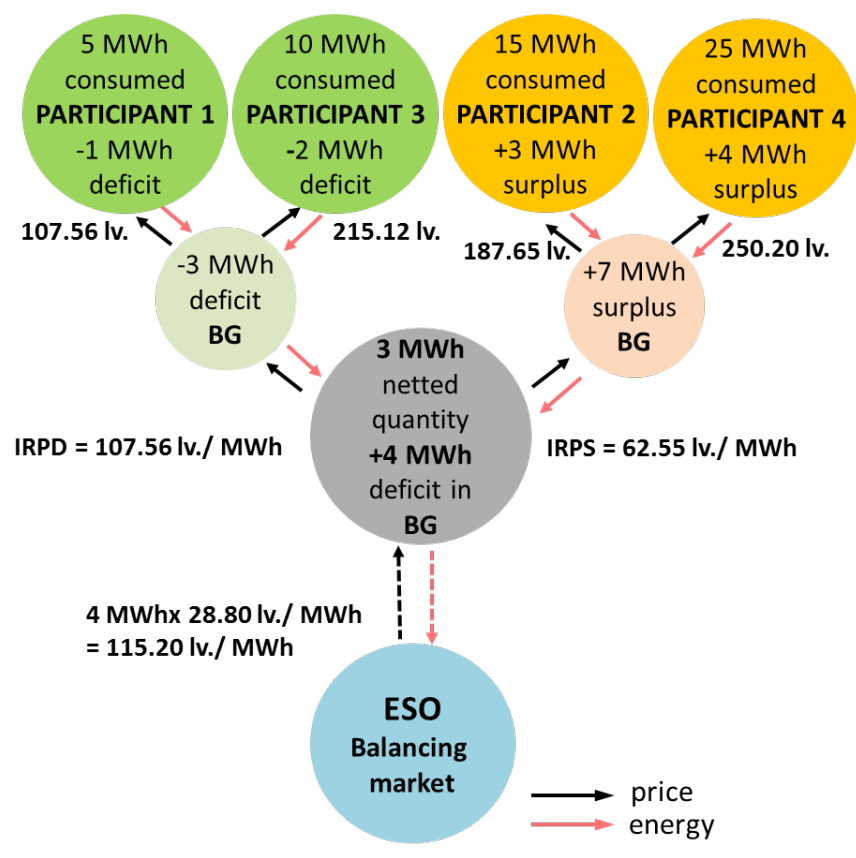

Development of a Method of Internal Reference Price for

Redistribution of Energy Imbalances in Balancing Groups

is netted (the positive value and the negative value neutralize each other) is $3 \mathrm{MWh}$, and the quantity to be realized on the balancing market of ESO is $4 \mathrm{MWh}$ surplus, that is to say that there is a situation of surplus in the group.
Fig 1 Method of Internal Reference Price

The financial result for the participants in the group is calculated using the following parameters:

$$
\begin{aligned}
& \text { PESeso }=28.80 \mathrm{lv} . / \mathrm{MWh} \\
& \text { PEDeso }=186.31 \mathrm{lv} . / \mathrm{MWh} \\
& I T P_{t}=\left(\frac{\text { PESeso }_{t}+\text { PEDeso }_{t}}{2}\right)= \\
& =\frac{(28.80+186.31)}{2}=107.56 \mathrm{lv} . / \mathrm{MWh}
\end{aligned}
$$

In order to calculate the effect of the participation in the BG for each participant it is necessary to calculate the internal reference price of surplus and deficit.

The internal reference price of surplus is calculated as follows:

$$
\begin{aligned}
I R P S_{t} & =\frac{N S_{t} \times I T P_{t}+\sum \text { QESeso }_{t} \times \text { PESeso }_{t}}{\left|\sum Q E S_{t}\right|}= \\
& =\frac{3 \times 107.56+4 \times 28.80}{7}=62.55 \mathrm{lv} . / \mathrm{MWh}
\end{aligned}
$$

The internal reference price of deficit is calculated as follows:

$$
\begin{aligned}
I_{\text {IRPD }} & =\frac{N D_{t} \times I T P_{t}+\sum \text { QEDeso }_{t} \times \text { PEDeso }_{t}}{\left|\sum Q E D_{t}\right|}= \\
& =\frac{3 \times 107.56+0 \times 186.31}{3}=107.56 \mathrm{lv} . / \mathrm{MWh}
\end{aligned}
$$

As the total quantity of energy deficit is netted, then the internal $I R P D_{t}$ is equal to $\operatorname{ITP}_{t}$.

In this particular case, participant 1 has produced $1 \mathrm{MWh}$ of deficit, which they will 


\section{Articles}

have to pay according to $I R P D_{t}$ or 107.56 IV./MWh. If participant 1 had chosen not to participate in a $B G$, they would have had to pay for this $1 \mathrm{MWh}$ at the price of deficit on the balancing market of ESO of $186.31 \mathrm{IV}$./ MWh., which is by $78.75 \mathrm{Iv}$. higher (or by $73 \%$ more).

Participant 3 has produced a deficit of 2 MWh, which they will have to pay according to $I R P D_{t}$ at $107.56 \mathrm{Iv}$./MWh or $215.12 \mathrm{Iv}$. If participant 3 had chosen not to participate in a BG, then they would have paid $372.62 \mathrm{Iv}$. for these $2 \mathrm{MWh}$, which is by $157.50 \mathrm{lv}$. higher (or by $73 \%$ more).

Participant 2 has produced a surplus of $3 \mathrm{MWh}$, which the CBG will pay according to $I R P S_{t}$ at $62.55 \mathrm{Iv}$./MWh or $187.65 \mathrm{Iv}$. If they had chosen not to participate in a BG, then they would have received $86.40 \mathrm{Iv}$. for these 3 MWh. from the balancing market, which is by $101.25 \mathrm{lv}$. less (or by $54 \%$ less).

Participant 4 has produced a surplus of $4 \mathrm{MWh}$, which the CBG will pay according to $I R P S_{t}$ at $62.55 \mathrm{Iv}$./MWh or $250.20 \mathrm{lv}$. If they had chosen not to participate in a BG, then they would have received $115.20 \mathrm{Iv}$. for these $4 \mathrm{MWh}$ from the balancing market, which is by $135 \mathrm{Iv}$. less (or by $54 \%$ less).
In the above presented method period $t$ can coincide with the period of settlement. Then for a period of settlement the internal reference price is static.

In order to be more precise with the calculations and to motivate the participants to be more precise in planning the hourly schedules, CBG can calculate the reference price of surplus and deficit per hour and not only for a period of settlement (which as of January 2015 is with a duration of 1 month).

In that case period $t$ is equal to $1 \mathrm{~h}$ and the reference price changes accordingly. The authors have named that reference price dynamic internal reference price.

\section{RESULTS AND DISCUSSIONS - APPLICATION OF THE METHOD}

For the purposes of this research the authors examine a real balancing group with seven participants and their hourly consumption within a month. Table 1 shows the summarized information for April 2014 about the negotiated $\mathrm{EE}$, the real quantity that was measured, the quantity of surplus and the quantity of energy deficit, the quantities of imbalances in the BG, netted quantities in the $B G$ and the quantities for the balancing market of ESO.

Table 1: Summarized results by participants and for the whole BG for April 2014

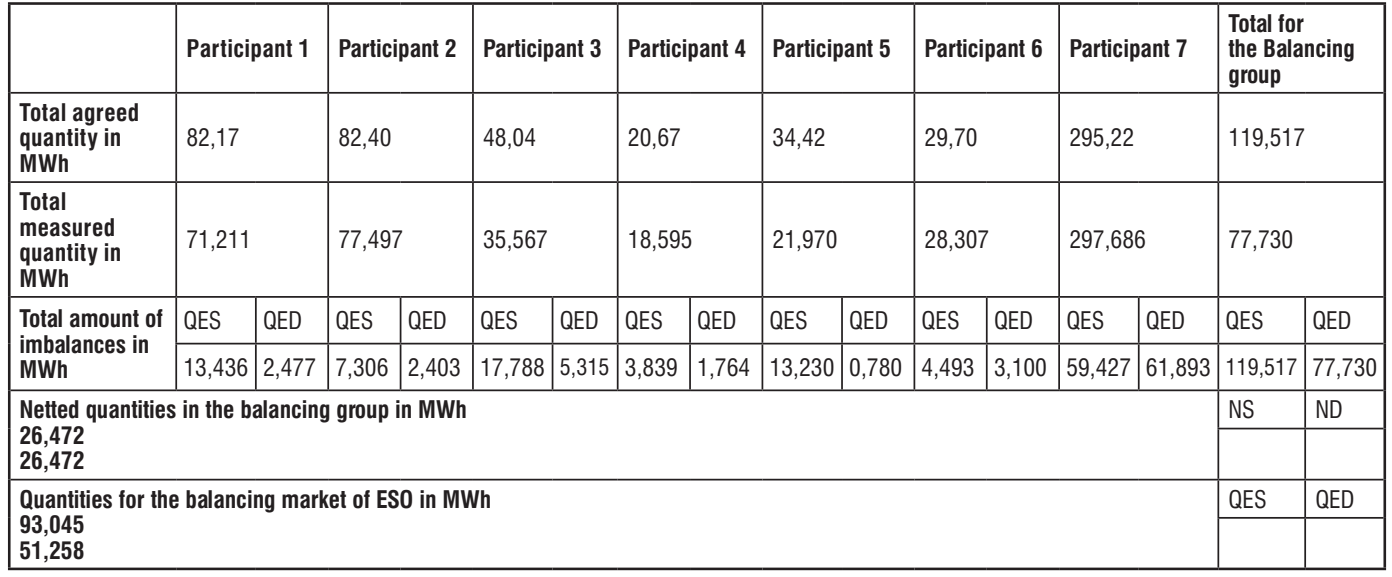




\section{Articles}

For the purposes of this analysis we will use again the values of the ESO average prices for May 2014 - surplus price of 28,80 Iv./MWh. and a deficit price of 186,31 Iv./ MWh. The authors have used the data for May 2014 because after that the data about the surplus and deficit prices are not public and are individual for each market participant.

As a basis of comparison the authors use the result, which would be achieved, if each participant did not participate in a balancing group and is self-balancing. In that case the deficit price, they would have paid would have been the highest, the surplus price they would have received, would have been the lowest.

Table 2 presents the results for each selfbalancing participant on the market of ESO on the basis of the average ESO prices of surplus and deficit for May 2014.

The data about the quantity of energy surplus (QES) and the quantity of energy deficit (QED) for each participant have been taken from Table 1.
Development of a Method of Internal Reference Price for

Redistribution of Energy Imbalances in Balancing Groups

The financial result about revenue $\left(F R R_{t}^{i}\right)$ for each participant has been calculated for a quantity of energy surplus (QES) for participant $i$, for period $t$ using the following formula:

$$
F R R_{t}^{i}=Q E S_{t}^{i} \times \text { PESeso }_{t}
$$

where:

$Q E S_{t}^{i}$ is the quantity energy surplus of participant $i$ for period $t$;

$\mathrm{PESeso}_{t}$ is the price of energy surplus of ESO for period $t$.

The financial result about expenditure $\left(F R E_{t}^{i}\right)$ for each participant has been calculated for a quantity of energy deficit (QED) for participant $i$, for period $t$ using the following formula:

$$
F R E_{t}^{i}=Q E D_{t}^{i} \times \text { PEDeso }_{t}
$$

where:

$Q E D_{t}^{i}$ is the quantity of energy deficit of participant $i$ for period $t$;

$\mathrm{PEDeso}_{t}$ is the price of energy deficit of ESO for period $t$.

\begin{tabular}{|c|c|c|c|c|c|c|c|c|}
\hline \multirow{3}{*}{$\begin{array}{l}\text { Quantity imbalances } \\
\text { in MWh }\end{array}$} & \multicolumn{2}{|c|}{ Participant 1} & \multicolumn{2}{|c|}{ Participant 2} & \multicolumn{2}{|c|}{ Participant 3} & \multicolumn{2}{|c|}{ Participant 4} \\
\hline & QES & QED & QES & QED & QES & QED & QES & QED \\
\hline & 13,436 & 2,477 & 7,306 & 2,403 & 17,788 & 5,315 & 3,839 & 1,764 \\
\hline \multirow{3}{*}{$\begin{array}{l}\text { Financial result in } \\
\text { BGN }\end{array}$} & revenue & expenditure & revenue & expenditure & revenue & expenditure & revenue & expenditure \\
\hline & 386,957 & 461,490 & 210,398 & 447,610 & 512,287 & 990,191 & 110,549 & 328,558 \\
\hline & \multicolumn{2}{|c|}{ Participant 5} & \multicolumn{2}{|c|}{ Participant 6} & \multicolumn{2}{|c|}{ Participant 7} & \multicolumn{2}{|c|}{ Total for the BG } \\
\hline \multirow{2}{*}{$\begin{array}{l}\text { Quantity imbalances } \\
\text { in MWh }\end{array}$} & QES & QED & QES & QED & QES & QED & QES & QED \\
\hline & 13,230 & 0,780 & 4,493 & 3,100 & 59,427 & 61,893 & 119,517 & 77,730 \\
\hline \multirow{2}{*}{$\begin{array}{l}\text { Financial result in } \\
\text { BGN }\end{array}$} & revenue & expenditure & revenue & expenditure & revenue & expenditure & revenue & expenditure \\
\hline & 381,017 & 145,275 & 129,406 & 577,608 & 1711,483 & 11531,192 & 3442,097 & 14481,923 \\
\hline
\end{tabular}

Table 2: Self-balancing on ESO balancing market

With each participant the imbalance generated for the month, respectively deficit and/or surplus is multiplied by the ESO prices.

With the balancing methods of evaluating the effect of balancing it necessary to use the internal trading price of the balancing group. That is the price at which the balancing energy is traded in the balancing group. That price is determined by the coordinator of the balancing group and can be based on ESO prices, on the market price, on a negotiated price and a trade bonus for the coordinator.

For the purposes of this analysis the internal trading price has been calculated as the mean value of the surplus and deficit prices of ESO using the formula (1), by calculating the price per hour $h_{i}$ : myk смисъ^ът е неясен 


$$
\begin{aligned}
I P^{h_{i}} & =\frac{\left(\text { PESeso }^{h_{i}}+\text { PEDeso }^{h_{i}}\right)}{2}=\frac{(28.80+186.31)}{2}= \\
& =107.56 \mathrm{lv} . / \mathrm{MWh}
\end{aligned}
$$

Before applying the methods of balancing we have to determine the netted quantity, respectively, netted surplus and deficit in the sample BG.

The quantity in a group, which is netted for period $t$, is determined on the basis of the quantity of energy surplus /QES/ and the quantity of energy deficit /QED/ in the group, i.e. the positive value and negative value neutralize each other, and depending on the result, if it is positive we get netted surplus / $\mathrm{NS} /$, and respectively, if it is negative we have a deficit /ND/, by using the formula (2), by calculating the price per hour $h_{i}$ :

$$
N S_{t}^{h_{i}}=N D_{t}^{h_{i}}=\left|\sum Q E S_{t}^{h_{i}}-\sum Q E D_{t}^{h_{i}}\right|
$$

where:

$N S_{t}^{h_{i}}$ is the quantity of surplus in MWh, netted in a group for period $t$;

$N D_{t}^{h_{i}}$ is the quantity of deficit in MWh, netted in a group for period $t$;

$\sum Q E S_{t}^{h_{i}}$ is the sum of the quantities of energy surplus of all participants in a group for period $t$;

$\sum Q E D_{t}^{h_{i}}$ is the sum of the quantities of energy deficit of all participants in a group for period $t$.

In the sample BG netting is done by the hour, i.e. period $t$ it is equal to 1 hour.
The calculation of the netted quantities is given in column "Netted quantities" in Table 1.

The sum of all hourly netted quantities is equal to $26.472 \mathrm{MWh}$.

Using the method of internal reference price, the reference price is the price in the group, according to which all imbalances, regardless of whether they are netted or are realized on the balancing market, are paid for.

The reference price can be static for a certain period of balancing (day, week, month, etc.) or dynamic, when calculated every hour. The CBG determines whether the price will be dynamic or static taking into consideration various factors such as the number of participants, market dynamics, the quantity of consumption and others. The CBG must present to the participants the way the reference price is formed in advance.

The reference price can be calculated as the mean value of the price of the balancing market for the surplus and the deficit and the price of balancing in a balancing group for a certain period (hour, day, week, month, etc.).

In the reference a price the CBG can include an additional coefficient, e.g. the coefficient of preciseness of the forecast or a bonus for CBG.

This particular study uses the static reference price for one month without any additional coefficients. The results are shown in Table 3. 


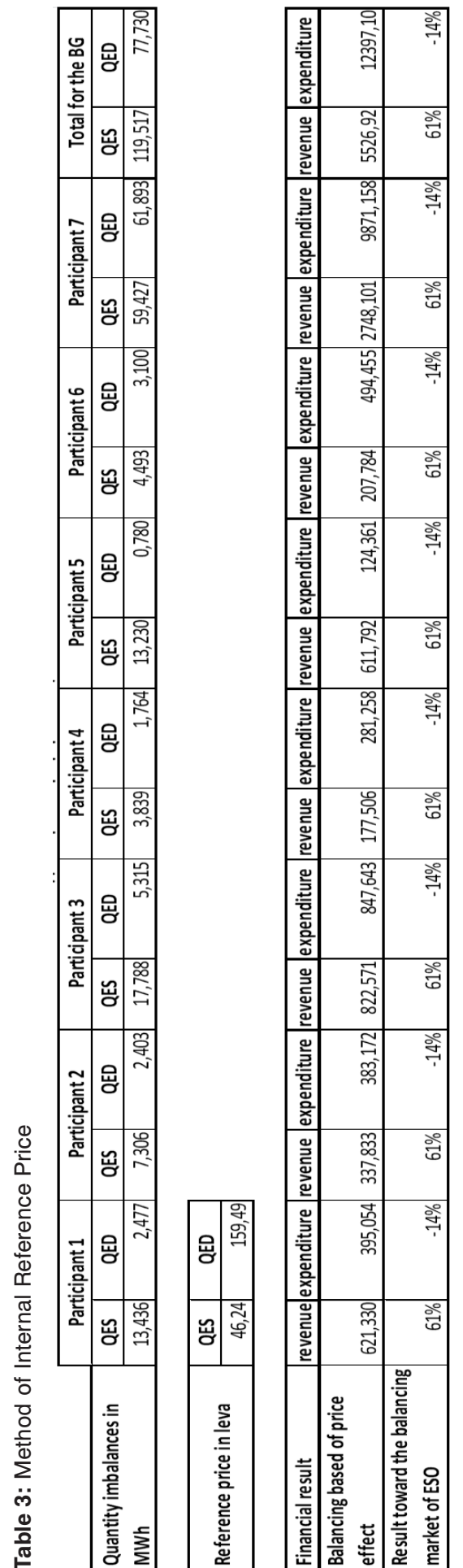

The reference surplus price is 46.24 Iv./ $\mathrm{MWh}$, and the reference deficit price is $159.49 \mathrm{IV}$./MWh. On the basis of these reference prices, respectively of deficit and/ or surplus, we have calculated the financial result for each participant in the group. For each participant the effect of the participation in the group is the same, respectively $+61 \%$ for the surplus they have and $-14 \%$ for the deficit they have run (Table 3 - Result toward the balancing market of ESO).

The method demonstrates fairness to the participants. A potential drawback would be a complex or incomprehensible, for the participants in the group, formation of the reference price by the $\mathrm{CBG}$.

The effectiveness of the developed method depends on the weight of each of the factors affecting the balancing group.

The main factors, which according to the authors influence the work of $C B G$ and $B G$ are as follows:

- Number and size of participants - The greater the number of participants, the greater the probability of netting the bigger part of the imbalance increases. Large consumers pay more attention to forecasting their consumption and may be more accurate in the forecasts, but even small percentages may affect the whole group if the other participantsare very small. In such cases, the choice of method is very important because it may be that the big participant picks up the imbalances of the smaller ones, but there is no one to cover its own imbalances and in practice it may turn out that it does not benefit from participating in the group.

In any case, the more participants in a balancing group, the more effective it will be for its participants.

- Stakeholder profiles of the group Combining participants with the same profile would create a lack of balancing ability, in which case the accuracy of 


\section{Articles}

the forecast is a key criterion for the effectiveness of balancing methods. For groups with complementary profiles, the simplest methods can be used without the need for additional coordinator engagement. Verifying the participant's profile and evaluating its compatibility with the members of the already established balancing group is a key task of the CBG before the respective participant is admitted to the group. The analysis of the load profile of each participant in the balancing group is based on historical data on actual consumption. The longer the analysis period, the better the analysis can be, because it covers the entire working cycle, seasonal fluctuations, planned repairs, etc.

In the case of large industrial users, the prediction of the load profile is usually done by their main engineers, while for small consumers who lack history and experience with this type of activity, this role is taken by the CBG. In cases where charging schedules are performed by the Balancing Group Coordinator (KGG), it is very important to have a constant and accurate exchange of information, e.g. for planned repairs, accidents, increase/decrease of production capacities and other factors that may affect the consumption of EE.

- Transparency and comprehensibility of the balancing methodology - The method of balancing is at the core of the activity of the CBG. At the same time, however, it is also important for the participants in the group because the choice of a suitable method depends on the aggregated group effect. The method should reflect all the factors affecting group performance and evolve with the needs and changes in the group, changes in the number of members, change in the consumption profile, change in the market situation, etc.
- Administration of the method - Any method of distribution of the imbalances must allow for practical application. Many theoretically constructed methods may not work in practice due to their inability to perform technically. In this case, the CBG should consider the chosen method with the capabilities of the group, the accessibility of information from external sources Electricity System Operator (ESO), network companies), market practices, etc. An additional factor to consider is the ability to use software to manage the method. Not every coordinator has the resources to create and maintain appropriate software.

- Fair distribution of imbalances - The balancing method must ensure a fair distribution of the imbalances so that each participant feels a full member of the group. In order to achieve this, the coordinator must choose and sell what is understandable to the participants in the group, ensuring their maximum benefit from the participation.

- Sustainability and predictability of results - Any method of distribution of the imbalances must ensure relatively stable results over a long period of time and do not require frequent adaptation by the CBG due to changes in various factors. For example, the frequent changes in the prices of the balancing market of ESO $E A D$ may create a sense of inaccuracy in the methods.

It can be noted that each CBG is free to judge for itself which method is optimal for its balancing group. Depending on the situation, each method can be optimal. In order for the CBG to choose the right method, it is necessary to analyze and evaluate the effectiveness of the different methods with respect to its balancing group. There are no restrictions in the period of using the selected method, i.e. depending on the 


\section{Articles}

impact of changing conditions in the group (e.g. change in the number of members or change in energy profiles) and / or outside the group (e.g. change in the organization of the electricity market) CBG chooses when to apply the method chosen by them, resp. to change it to another, with which it will make better results for itself and the members of BG.

As the authors have already noted, the CBG is responsible for choosing a method for distributing the imbalances.

\section{FINDINGS OF THE ADOPTION OF THE DEVELOPED METHOD}

On the basis of the trial and the simulations that have been carried out with the here developed method of the distribution of energy imbalances in a BG we can draw the following conclusions:

1. The method of optimal distribution of energy imbalances in a BG, which has been developed on a theoretical basis, is applicable in real balancing groups;

2. The methodological approach of using the method of optimal distribution of energy imbalances in a BG makes it possible to calculate the financial impact of the participation of each participant in the respective $B G$;

3. The method yields a better financial result for the participants in the trial $B G$ than from an independent balancing on the balancing market of ESO.

When this method is adopted the following results are achieved:

1. There is a distribution of the result from the participation in the BG among its participants;

2. The financial effect for each participant from their participation in the $B G$ can be calculated;

3. The use of the method brings positive financial result for the participants in the $B G$
Development of a Method of Internal Reference Price for

Redistribution of Energy Imbalances in Balancing Groups

when compared to independent balancing on the balancing market of ESO;

The application of the method of internal reference price demonstrates highly positive results and proves it possible to use in a real BG.

\section{CONCLUSIONS \& RECOMMENDATIONS}

As it has already been pointed out, the CBG chooses and develops a method of distribution of the Imbalances, always following one and the same general market principles, concerned with fairness, equality, transparency and financial effectiveness.

The method of internal reference price is a universal method, which can be used in cases when CBG does not have enough information about energy consumption and the precision of planning by the participants. It is appropriate for groups with many participants of varied consumption.

With the method of internal reference price, the effect for the participants is equal and proportionate to the produced imbalance. With this method, as it has already been pointed out, there is no physical netting, but only the financial flows are used, and the final effect for the participants is equal. It is important to use this methodology to get this result. In this case, a reference price is used, which gives participants a clear idea of their expenditure for, respectively, revenue from balancing energy.

The rate at which the real electrical energy market in the country is developing implies that CBGs should not only manage imbalances but also offer complex services related to trading and management of the energy consumption of the group participants. That means that CBGs should develop their methods so that they are more effective, for example, the CBG could include in their method a coefficient of precision, which is 
based on the deviation, in percentage, from the preciseness of the forecast.

\section{REFERENCES}

Angelova J. (2008). Determination of the price of electric power, King, S.

Angelova J., Ts. Nedeva (2004). Oligopoly prices and solutions for price games in the balancing electricity market, IM magazine, issue 1, p.41-46, ISSN1312-3793.

Bonev K. et al. (1997). Mathematical methods for the study of operations, Mathematical methods in economics.

Donchev D., J. Angelova (2003) Possibility to use the balancing electricity prices for the improvement of the electricity market, 1st International Conference "Ml", S., VI.

Kenderov P., G. Hristov, A. Donchev (1989). Mathematical optimization, Sofia: University Press "St. KI. Ohridski"

Medic, J. (1985). Methods for data analysis. M. "Finance and Statistics".

SEWRC (2014) Method for Determining Balancing Energy Prices, Annex to Art. 105, para. 4 of the Rules for Trade in Electricity, amend. and dop. SG. No. 39.

Anderson, L.G. and Settle, R.F. (2002). Benefit-Cost Analysis: A Practical Guide, Lexington, Massachusetts, Toronto: Lexington Books, D.C.Heath and Company.

Barz, Craydon L. (2000). Stochastic financial models for electricity derivaties, Standford University: Dissertation.

Chris Harris (2006). Electricity Markets: Pricing, Structures and Economics, Wiley Finance.

Darryl R. Biggar, Mohammad Reza Hesamzadeh (2014). The Economics of Electricity Markets, Wiley - IEEE.

Jörg Borchert, Ralf Schemm, Swen Korth, Stromhandel (2006). Institutionen, Marktmodelle, Pricing und Risikomanagement, Schäffer Poeschel.

Rafal Weron (2006). Modeling and Forecasting Electricity Loads and Prices.

Wolfgang Zander, Martin Riedel, Christian Held (2000). Strombeschaffung im liberalisierten Energiemarkt, Deutscher Wirtschaftsdienst. 